\title{
Ulcer Size and Gastric Cancer Prognosis
}

\author{
Levent Filik \\ Gastroenterology Division, Ankara Research Hospital, Ankara, Turkey
}

Dear Sir,

I read with great interest the article by $\mathrm{Xu}$ et al. [1]. The authors present the ulcer size as a novel prognostic criterion for gastric cancer. The authors also emphasize the preoperative predictive use of ulcer size. In fact, it is not surprising that the patients with larger tumors and wider ulcers have greater invasion into the gastric wall in terms of depth of invasion and more frequent lymph node metastasis than the patients with smaller ulcers. However, there is one item missing. Nearly half of gastric cancers are fungating or polypoid and we cannot ignore these patients. Moreover, there is considerable overlap between dif- ferent types of macroscopic appearances (polypoid, ulcerative, fungating) of gastric cancer. Accordingly, several studies have already shown the prognostic importance of tumor size $[2,3]$. In their study, there is a significant relationship between ulcer size and tumor size $(4 \mathrm{~cm})$. In the $\mathrm{U} 2$ group (ulcer $>3 \mathrm{~cm}$ ), $94 \%$ of the patients had tumor diameters $>4 \mathrm{~cm}$. If the authors had chosen to compare tumor size of $5 \mathrm{~cm}$ instead of $4 \mathrm{~cm}$, it might have been $100 \%$. For that reason, I think that tumor size is a much better prognostic criterion than ulcer size in clinical practice when we consider all gastric cancer patients.

\section{References}

$\checkmark 1$ Xu CY, Shen JG, Shen JY, Chen WJ, Wang LB: Ulcer size as a novel indicator marker is correlated with prognosis of ulcerative gastric cancer. Dig Surg 2009;26:312-316.

$\checkmark 2$ Yokota T, Ishiyama S, Saito T, Teshima S, et al: Is tumor size a prognostic indicator for gastric carcinoma? Anticancer Res 2002;22: 3673-3677.

3 Kim JP, Lee JH, Kim SJ, Yu HJ, Yang HK: Clinicopathologic characteristics and prognostic factors in 10,783 patients with gastric cancer. Gastric Cancer 1998;1:125-133.

\section{Reply \\ L.B. Wang ${ }^{\mathrm{a}}$ C.Y. Xu $\mathrm{u}^{\mathrm{a}, \mathrm{b}} \quad$ J.G. Shen ${ }^{\mathrm{a}}$ \\ aDepartment of Surgical Oncology, Sir Run Run Shaw Hospital, Zhejiang University College of Medicine, and \\ bSir Run Run Shaw of Clinical College of Medicine and Key Laboratoy of Biotherapy of Zhejiang \\ University Province, Hangzhou, China}

Dear Sir,

We sincerely appreciate Dr. Filik's comments. He mentioned that half of gastric cancers are fungating or polypoid, apart from ulceration gastric cancer. We agree that there are different types of gastric cancer. However, the aim of our study was to investigate the relationship between ulcer size and patient survival. Therefore, we only selected the ulcerative gastric cancer patients.
Dr. Filik also mentioned that $94 \%$ of patients in the $\mathrm{U} 2$ group (ulcer size $>3 \mathrm{~cm}$ ) have tumor size $>4 \mathrm{~cm}$, and this result may possibly lead to the idea that all patients with ulcer size $>3 \mathrm{~cm}$ might have tumor size $>5 \mathrm{~cm}$. However, our results showed that $80 \%$ of patients in the U2 group had tumor size $>5 \mathrm{~cm}$. The significant relationship between ulcer size and tumor size can be confirmed in any study. Whether or not the tumor size is an independent factor in survival in gastric cancer is still controversial. Kim et al. [1] analyzed 10,783 gastric cancer patients, and the results showed the tumor size had a prognostic significance on univariate analysis, but it was not an independent factor on multivariate analysis or an independent predictor of survival. Yokota et al. [2] showed a similar result. However, another paper showed that tumor size may be an independent predictor of survival [3].

\section{KARGER}

Fax +4161306 1234 E-Mail karger@karger.ch www.karger.com
(C) 2010 S. Karger AG, Basel

0253-4886/10/0273-0248\$26.00/0

Accessible online at:

www.karger.com/dsu
Dr. Levent Filik

Ankara Research Hospita

Gastroenterology Division

Altindag, TR-06600 Ankara (Turkey)

Tel. +90 312595 4272, E-Mail leventfilik@yahoo.co.uk 
In our study, only patients with ulcerative gastric cancer were included in the analysis. Our study as well as the ones mentioned above showed that tumor size was not a predictor of survival in ulcerative gastric cancer patients. This discordant result may be influenced by gastric cancer stage, mean tumor size, number of patients studied, etc.

\section{References}

Kim JP, Lee JH, Kim SJ, et al: Clinicopathologic characteristics and prognostic factors in 10,783 patients with gastric cancer. Gastric Cancer 1998;1:125-133.

2 Yokota T, Ishiyama S, Saito T, Teshima S, et al: Is tumor size a prognostic indicator forgastric carcinoma? Anticancer Res 2002;22: 3673-3677.

-3 Adachi Y, Oshiro T, Mori M, et al: Tumor size as a simple prognostic indicator for gastric carcinoma. Ann Surg Oncol 1997;4:137-140.
L.B. Wang

Department of Surgical Oncology

Sir Run Run Shaw Hospital Zhejiang

University College of Medicine

Hangzhou 310016 (China)

Tel. +865718600 6912, Fax +865718604 4817

E-Mail wanglinbo@ medmail.com.cn 